\title{
Evaluation on gas production potential from laminar hydrate deposits in Shenhu Area of South China Sea through depressurization using vertical wells
}

\author{
Zheng Su ${ }^{\mathrm{a}, \mathrm{b}}$, Yong He ${ }^{\mathrm{a}, \mathrm{b}}$, Nengyou Wu ${ }^{\mathrm{a}, \mathrm{b}, *}$, Keni Zhang ${ }^{\mathrm{c}}$, George J. Moridis ${ }^{\mathrm{d}}$ \\ a Key Laboratory of Renewable Energy and Gas Hydrate, Guangzhou Institute of Energy Conversion, Chinese Academy of Sciences, Guangzhou 510640, China \\ b Guangzhou Center for Gas Hydrate Research, Chinese Academy of Sciences, Guangzhou 510640, China \\ c College of Water Sciences, Beijing Normal University, Beijing 100875, China \\ d Lawrence Berkeley National Laboratory, Berkeley, CA 94702, USA
}

\section{A R T I C L E I N F O}

Article history:

Received 13 February 2011

Accepted 14 March 2012

Available online 27 March 2012

\section{Keywords:}

gas hydrates

hydrate dissociation

depressurization

numerical simulation

\begin{abstract}
A B S T R A C T
Gas hydrates are solid crystalline compounds in which gas molecules are lodged in lattices of ice crystals. Shenhu area is considered as one of the most promising fields on north continental slope of the South China Sea (SCS). Drilling and sampling at the site has indicated occurrences of methane hydrate in clay silty sediments. The thin Hydrate-Bearing Layer (HBL) is overlain and underlain by zones of mobile water, and the layer does not appear to be bounded by low-permeability strata. In this study we assess by means of numerical simulation the production potential of the laminar hydrate deposit at drilling site SH3 in the Shenhu area. We simulate the hydrate dissociation and the gas production induced by depressurization at a vertical well. To minimize gas losses through the overburden and excessive water production through proximity to the permeable, water-saturated zones, a perforated interval is limited to the middle section of the vertical well within the hydrate layer. The simulations show that productions from depressurization-induced dissociation through a vertical well at constant well pressure do not appear to be a promising approach in the deposits of low hydraulic diffusion. The production of hydrate-originating gas decreases at the beginning of the production and then keep stable in the reference case and the average production is $211 \mathrm{~m}^{3} / \mathrm{d}$. The deposit permeability is considered as the most insensitive parameter to enhance the gas production. And the production potential is much lower than that of deposits having an impermeable upper boundary as expectation.
\end{abstract}

(c) 2012 Elsevier B.V. All rights reserved.

\section{Introduction}

Gas hydrates are crystalline substances composed of water and gas, in which a solid water lattice accommodates gas molecules in a cage-like structure (Sloan, 1998). The estimated amount of gas in the hydrate accumulations of the world greatly exceeds the volume of known conventional gas resources (Sloan, 1998). Because of their potential importance as an energy resource, $\mathrm{CH}_{4}$-hydrates are currently attracting significant attention. However, the role that gas hydrates may play in contributing to the world's energy requirements will depend ultimately on the availability of producible gas hydrate resources and the cost to extract them (Moridis et al., 2004).

The three main methods of hydrate dissociation for producing gas include (Makogon, 1987, 1997): (1) depressurization, in which the pressure is lowered to a level lower than the hydration pressure $\mathrm{P}_{\mathrm{H}}$ at the prevailing temperature (Moridis et al., 2007, 2009a); (2) thermal

\footnotetext{
* Corresponding author at: Key Laboratory of Renewable Energy and Gas Hydrate, Guangzhou Institute of Energy Conversion, Chinese Academy of Sciences, Guangzhou 510640, China. Tel.: + 862087052746.

E-mail address: wuny@ms.giec.ac.cn (N.Wu).
}

stimulation, in which the temperature is raised above the hydration temperature $T_{H}$ at the prevailing pressure (Moridis et al., 2004); and (3) the use of inhibitors (such as salts and alcohols), which causes a shift in the $\mathrm{P}_{\mathrm{H}}-\mathrm{T}_{\mathrm{H}}$ equilibrium through competition with the hydrate for guest and host molecules (Sloan, 1998). In gas production from hydrate deposits depressurization and thermal stimulation are considered as the relatively feasible method both economically and technically (Moridis and Reagan, 2007a,b; Moridis et al., 2009a,b, 2011).

Shenhu area is near southeast of the Shenhu Underwater Sandy Bench in the middle of the north slope of the SCS, between Xisha Trough and Dongsha Islands (Fig. 1). Geological, geophysical, geothermal, and geochemical investigations have suggested that Shenhu area is a favorable place for natural gas hydrate formation (Wu et al., $2008,2010)$. Based on the indications of hydrate presence, five sites were selected for deep drilling and sampling in Shenhu area (Fig. 1), and core samples were collected chronologically from SH3, SH1, SH2, SH7, and SH5 (Wu et al., 2008). Depressurization experiments verified existences of methane gas hydrates in the clay-silty cores sampled from $\mathrm{SH} 2, \mathrm{SH} 3$, and $\mathrm{SH} 7$ at the water depths of 1108-1245 m. Some simulations have provided the first insight into 


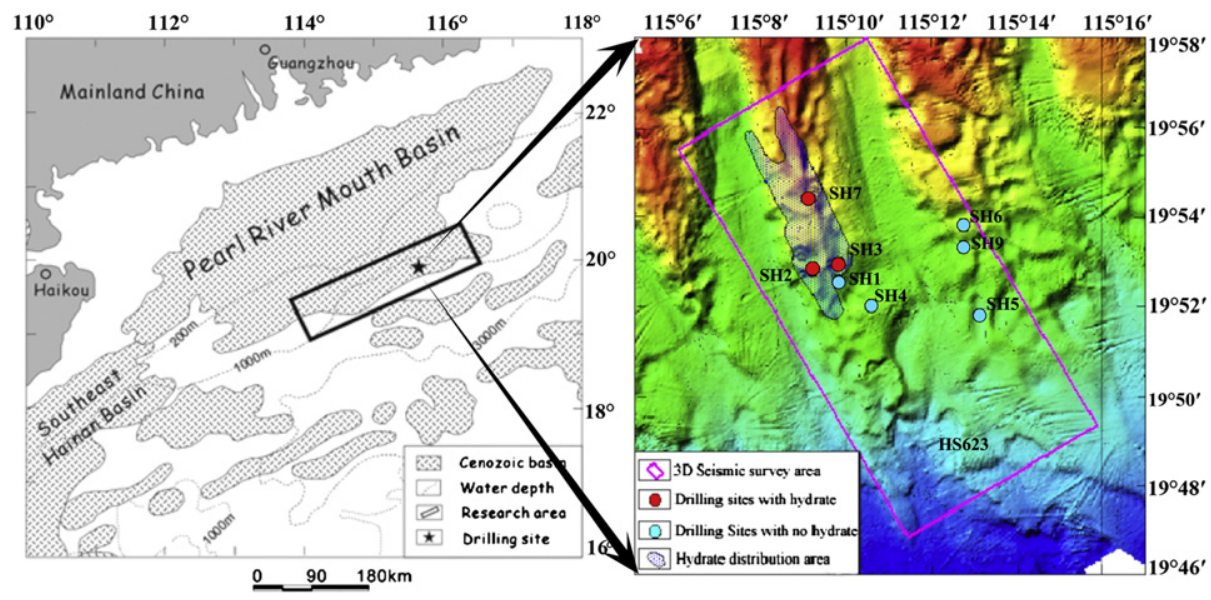

Fig. 1. Location of research field and drilling sites at Shenhu area on northern continental slope of South China Sea.

the technical feasibility of gas production from the promising accumulations at the very ideal conditions (Li et al., 2010; Su et al., 2010).

However, distributions of the Shenhu hydrate are extremely uneven. The HBL is $40 \mathrm{~m}$ thick and the hydrate saturation ranges from 0 to $48 \%$ at drilling site $\mathrm{SH} 2$. The hydrate accumulation at site $\mathrm{SH} 3$ is $10 \mathrm{~m}$ thick and the thinnest in the small area. Hydrate saturation are $12-25 \%$ and the average value is $20 \%$. The main objective of this study is to assess the production potential of the laminar hydrate deposit at Site SH3 by means of numerical simulation. Parameters used in the reference cases are measured from the samples, such as saturations, temperature and pressure, and deposit permeability is estimated based on the lithology. Because of possible imprecision of measured data from the unconsolidated samples and uncertain geological structure, a large number of these parameters are treated as perturbation variables in the ensuing sensitivity analysis. Previous researches show that the Shenhu hydrate accumulations are Class 2 deposits that comprise a HBL overlain and underlain by zones of mobile water (Li et al., 2010; Su et al., 2010). Therefore, this study focuses on the hydrate deposit and addresses the issues that may affect production from them.

In evaluating production potentials of hydrate deposits in Shenhu area, we use two criteria, an absolute criterion and a relative criterion (Moridis et al., 2007). To satisfy the absolute criterion, a large production potential must be demonstrated, as quantified by a large gas production rate $Q_{P}$, a large cumulative gas production volume $V_{P}$ over the duration of the production. The relative criterion is satisfied when the gas-to-water ratio $\mathrm{R}_{\mathrm{GW}}=\mathrm{V}_{\mathrm{G}} / \mathrm{V}_{\mathrm{W}}$ is high, indicating more gas produced relative to water production.

\section{Production design}

In this study we focused on the hydrate deposits of Class 2 that occurs at the site, which is also one of the most common classes of hydrate accumulations in both the permafrost and oceans (Moridis and Reagan, 2007a; Moridis et al., 2009a). Note that the reference case of Class 2 accumulation is confined between a permeable overburden and a permeable underburden. Without confining boundaries of impermeable strata, gas production can be disappointing because flow through the boundaries limits the effectiveness of depressurization and leads to large production volumes of undesirable water (Moridis and Kowalsky, 2006; Moridis et al., 2009a). Lack of a confining overburden could lead to gas loss though the overburden toward the surface (Moridis et al., 2009a).

A similar configuration of the well system is used in this study for producing gas from the SH3 hydrate deposit. It is a modification of well designs used in previous hydrate production researches (Moridis et al., 2009a; Su et al., 2010). A perforated interval covers the mid section of the well which is nested in the HBL $(6 \mathrm{~m})$ that is overlain and underlain by the permeable water zones (WZs) as shown in Fig. 2 schematically. This design has significant advantages: the configuration impedes water in the WZs from the flow directly into the well in the early stage of the production, thus it may effectively reduce water production as well as production cost. This design can cause significant dissociation around the well and yield the largest production rates in a short run, but when the hydrate sealing around the well is broken through, it may result in a sharp drop in hydrate dissociation and gas production rates, and a disappointing elevation in water production (Moridis et al., 2009a; Su et al., 2010).

Earlier studies (Moridis and Sloan, 2007; Su et al., 2010) appear to indicate that depressurization is the most promising dissociation method (and possibly the only practical option) in the majority of hydrate deposits because of its simplicity, technical and economic effectiveness, the fast response of hydrates to the rapidly propagating pressure wave, the near-incompressibility of water, and the large heat capacity of water. The latter plays a significant role in providing part of the heat needed to support the strongly endothermic dissociation reaction as warmer water flows from the outer reaches of the formation toward the well (Moridis et al., 2007). Numerical studies have shown that the other dissociation methods can enhance gas production when used in conjunction with depressurization (Li et al., 2010; Su et al., 2010), but tend to be ineffective when used as main dissociation strategies. In this study, the depressurization with

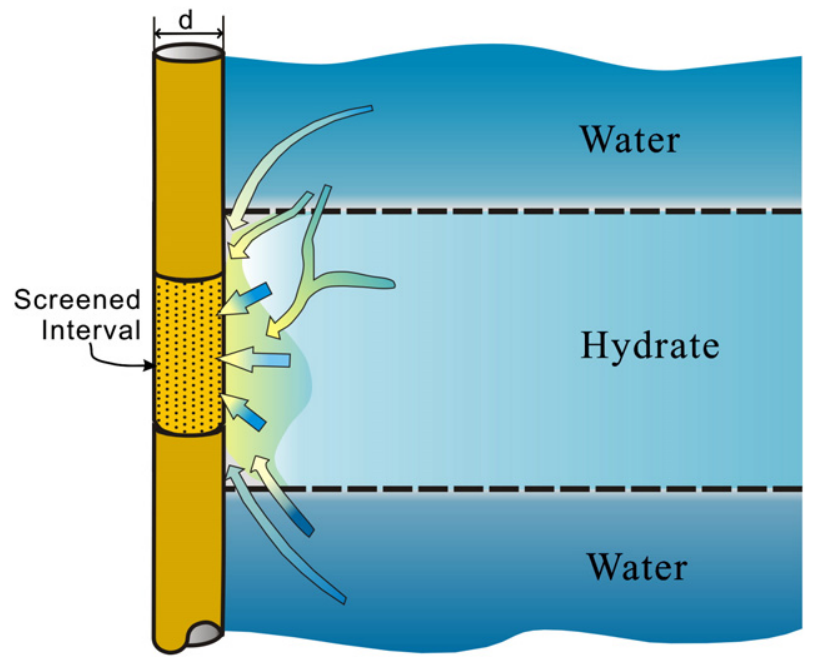

Fig. 2. Well design used in the gas production from SH3 hydrate deposit in Shenhu area, Southern China Sea (modified from Moridis et al., 2009a; Su et al., 2010). 
constant bottom-hole pressure is used to produce gas from the hydrate deposits in Shenhu area.

\section{Numerical models and simulation approach}

The numerical studies in this paper were conducted using the TOUGH + HYDRATE simulator (Moridis et al., 2009b). This code can model the non-isothermal hydration reaction, phase behavior, and flow of fluids and heat under conditions typical of natural $\mathrm{CH} 4-$ hydrate deposits in complex geologic media. It includes both an equilibrium and a kinetic model (Clarke and Bishnoi, 2000; Kim et al., 1987) of hydrate formation and dissociation. The model accounts for heat and up to four mass components (i.e., water, $\mathrm{CH}_{4}$, hydrate, and water-soluble inhibitors such as salts or alcohols) that are partitioned among four possible phases: gas, aqueous liquid, ice, and hydrate. A total of 15 states (phase combinations) can be described by the code, which can handle any combination of hydrate dissociation mechanisms and can describe the phase changes and steep solution surfaces that are typical of hydrate problems (Moridis et al., 2009b).

The geologic system in this study corresponds to a location at the drilling site of SH3 in the Shenhu area where the seafloor is at an elevation of $z=-1245 \mathrm{~m}$. The HBL is $10 \mathrm{~m}$ thick, and overlain by a permeable overburden of $190 \mathrm{~m}$ thick and underlain by a thick permeable zone. Both the overburden and underburden are unbounded and typical of water zones (WZs).

A geometry and configuration of Class 2 system at the drilling site of SH3 are shown in Fig. 3. The whole 190 m overlying sediment was considered as an overburden in simulations to allow heat exchange with the laminar hydrate layer during a 3.5-year long production period. Similarly, a 190 m underburden was sufficient to provide accurate estimates of heat transfer compared to that in the gas production from hydrate accumulation in the Ulleung Basin of the Korean East Sea (Moridis et al., 2009a). The well at the center of this cylindrical hydrate deposit had a radius $r_{w}=0.1 \mathrm{~m}$. A no-flow boundary (of fluids and heat) was applied at the reservoir at radius $r_{\max }=100 \mathrm{~m}$, the scale was enough for thermal transfer and fluid flow in production duration of 3.5 years by learning efficiency of heat transfer in marine sediment ( $\mathrm{Su}$ et al. 2011) and previous studies in the area (Li et al., 2010; Su et al., 2010).

The same grid and media properties were used in the simulations. The cylindrical domain was discretized into $100 \times 136=13,600$

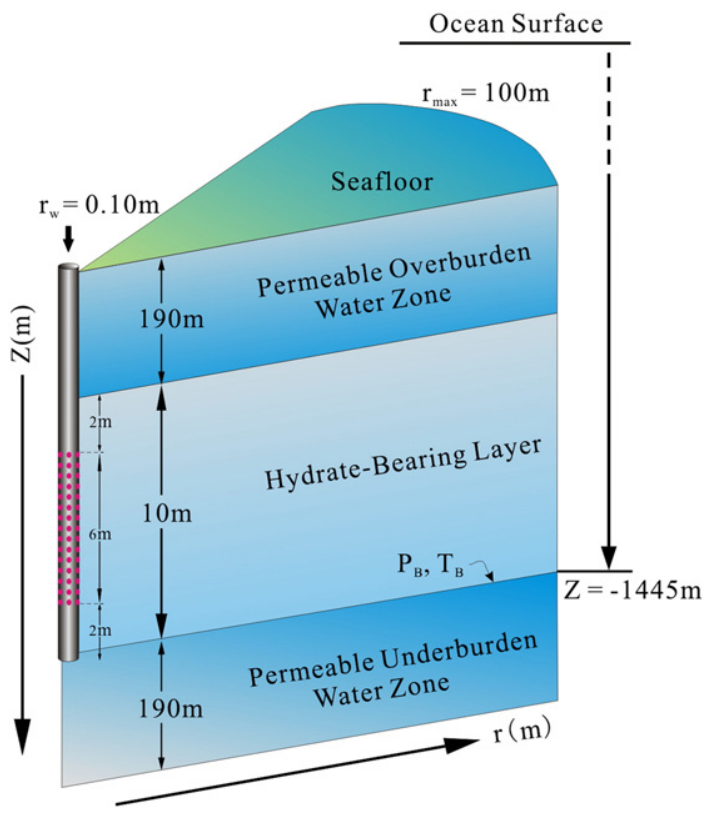

Fig. 3. A schematic depiction of the SH3 hydrate deposit simulated in this study. Modified from Moridis et al., 2009a; Su et al., 2010). gridblocks in ( $\mathrm{r}, \mathrm{z}$ ), of which 13,400 were active (the remaining being boundary cells). The uppermost boundary temperature is defined by the seafloor temperature and the lowermost layer corresponded to constant $\mathrm{T}$ calculated according to the geothermal gradient. Because the vicinity of the wellbore had been shown to be critically important to production (Moridis et al., 2009a; Su et al., 2010), a very fine discretization was used, and the interval increased exponentially along the $r$ direction. The HBL was subdivided into segments of $\Delta z=0.25 \mathrm{~m}$ each along the z-direction for accurate predictions, but a coarser discretization along the $\mathrm{z}$ axis is permissible in the WZ (Moridis et al., 2009a). We also assumed that the hydrate dissociation is an equilibrium reaction (Kim et al., 1987; Moridis et al., 2009a). The well design and important parameters were referenced from the early research of Shenhu hydrate production (Su et al., 2010).

Initial conditions in simulations were determined by following the initialization process described by Moridis et al. (2007, 2009a). Knowing (a) the elevation at the base of the HBL, and (b) some temperatures (Table 1), we determined the local geothermal gradient $\mathrm{G}_{\mathrm{T}}$ as $0.049{ }^{\circ} \mathrm{C} / \mathrm{m}$, and delineated the temperature profile at site $\mathrm{SH} 3$. Then the pressure profile was obtained by means of a short simulation with the temperature, salinity, and hydrate saturation.

\section{Depressurization using a vertical well}

Gas is produced from Class 2 hydrate deposits at site SH3 by removing reservoir fluids from a well operating at a constant bottomhole pressure $\mathrm{P}_{\mathrm{W}}$. A significant advantage of constant-P production is the elimination of the possibility of ice formation (with its detrimental effects on permeability and $Q_{P}$ ) through the selection of an appropriate pressure $P_{W}$ (Moridis et al., 2009a). This is ensured by selecting a $\mathrm{P}_{\mathrm{W}}>\mathrm{P}_{\mathrm{O}}$ (= $\mathrm{P}$ at the quadruple point). Constant-P production is the recommended depressurization method for gas production from the SH3 hydrate accumulations because of the very low permeability.

\subsection{Production from the reference case}

The properties and conditions pertaining to the reference case are listed in Table 2. Because the mass fraction of $\mathrm{CH}_{4}$ was greater than $99 \%$ of hydrate gases at site SH3, the guest gas used in simulations of this study was taken as pure methane. An average formation porosity of 0.38 and a medium hydrate saturation of 0.20 were used. An intrinsic permeability of $1.0 \times 10^{-14} \mathrm{~m}^{2}$ was used as the reference value of the whole system based on the lithology of silt clay. For avoiding ice plugging and enhancing production performance, the reference bottom-hole pressure was assigned to be $3 \mathrm{MPa}$ in the simulation on gas production through depressurization. The gas and aqueous phase production rates $\left(\mathrm{Q}_{p}\right.$ and $\mathrm{Q}_{W}$, respectively) are determined from the phase mobilities.

Fig. 4 shows the evolution of the volumetric rates (a) $Q_{p}$ of total $\mathrm{CH}_{4}$ flow produced at the well and (b) $\mathrm{Q}_{\mathrm{R}}$ of $\mathrm{CH}_{4}$ released from hydrates in the entire simulated domain. $Q_{P}$ and $Q_{R}$ decrease rapidly at the very beginning of the production and then are almost kept stable in a long run. $Q_{p}$ of gas production rate at the well is much greater

Table 1

Measured data of temperature at drilling site of SH3.

\begin{tabular}{|c|c|c|c|c|}
\hline Site & Sample & $\begin{array}{l}\text { Depth } \\
\text { (mbsf) }\end{array}$ & $\begin{array}{l}\text { Temperature } \\
\left({ }^{\circ} \mathrm{C}\right)\end{array}$ & $\begin{array}{l}\mathrm{G}_{\mathrm{T}} \\
\left({ }^{\circ} \mathrm{C} / \mathrm{m}\right)\end{array}$ \\
\hline \multirow[t]{7}{*}{ SH3 } & - & 0 & 3.5 & \multirow[t]{7}{*}{0.049} \\
\hline & SH3B-TEMP1 & 76 & 9.29 & \\
\hline & SH3B-TEMP 2 & 135 & 12.50 & \\
\hline & SH3B-FPWS1 & 137 & 12.35 & \\
\hline & SH3B-TEMP 3 & 197 & 15.24 & \\
\hline & SH3B-FPWS 2 & 199 & 15.43 & \\
\hline & SH3B-TEMP 4 & 215 & 16.18 & \\
\hline
\end{tabular}


Table 2

Reference hydrate deposit properties.

\begin{tabular}{|c|c|}
\hline Parameter & Value \\
\hline $\begin{array}{l}\text { Water zone (WZ) thickness } \\
\text { (overburden and underburden) }\end{array}$ & $190 \mathrm{~m}$ \\
\hline Hydrate zone (HBL) thickness & $10 \mathrm{~m}$ \\
\hline Radius of the simulation domain & $100 \mathrm{~m}$ \\
\hline Gas composition & $100 \% \mathrm{CH}_{4}$ \\
\hline Initial saturations in the $\mathrm{HBL}$ & $\mathrm{S}_{\mathrm{H}}=0.20, \mathrm{~S}_{\mathrm{A}}=0.80$ \\
\hline Water salinity (mass fraction) & 0.0334 \\
\hline $\begin{array}{l}\text { Intrinsic permeability } \mathrm{k}_{\mathrm{r}}=\mathrm{k}_{\mathrm{z}} \\
\quad(\mathrm{HBL} \text { and } \mathrm{WZ})\end{array}$ & $\begin{array}{l}1.0 \times 10^{-14} \mathrm{~m}^{2} \\
(=10 \mathrm{mD})\end{array}$ \\
\hline Grain density $\rho_{\mathrm{R}}$ (HBL and WZ) & $2600 \mathrm{~kg} / \mathrm{m}^{3}$ \\
\hline Porosity $\varphi$ (HBL and WZ) & 0.38 \\
\hline $\begin{array}{l}\text { Hydraulic diffusion } \mathrm{k}_{\mathrm{g}} \\
\quad \text { (Cathles, 2007) }\end{array}$ & $\mathrm{k}_{\mathrm{g}}=\mathrm{k} / \varphi \mathrm{C}_{\mathrm{g}} \mu_{\mathrm{g}}$ \\
\hline Compressibility $\mathrm{C}_{\mathrm{g}}$ & \\
\hline $\begin{array}{l}\text { Dry thermal conductivity } \mathrm{k}_{\Theta \mathrm{RD}} \\
\text { (all formations) }\end{array}$ & $1.0 \mathrm{~W} / \mathrm{m} / \mathrm{K}$ \\
\hline $\begin{array}{l}\text { Wet thermal conductivity } \mathrm{k}_{\Theta \mathrm{RW}} \\
\text { (all formations) }\end{array}$ & $3.1 \mathrm{~W} / \mathrm{m} / \mathrm{K}$ \\
\hline $\begin{array}{l}\text { Composite thermal conductivity model } \\
\text { (Moridis et al., 2007) }\end{array}$ & $\begin{array}{l}\mathrm{k}_{\Theta C}=\mathrm{k}_{\Theta R D} \\
+\left(S_{A}^{1 / 2}+S_{H}^{1 / 2}\right)\left(k_{\Theta R W}-k_{\Theta R D}\right)+\varphi S_{\mathrm{I}} k_{\Theta I}\end{array}$ \\
\hline $\begin{array}{l}\text { Capillary pressure model } \\
\text { (van Genuchten, 1980) }\end{array}$ & $\begin{array}{l}P_{\mathrm{cap}}=-\mathrm{P}_{0}\left[\left(\mathrm{~S}^{*}\right)^{-1 / \lambda}-1\right]^{-\lambda} \\
\mathrm{S}^{*}=\left(\mathrm{S}_{\mathrm{A}}-\mathrm{S}_{\mathrm{irA}}\right) /\left(\mathrm{S}_{\mathrm{mxA}}-\mathrm{S}_{\mathrm{irA}}\right)\end{array}$ \\
\hline $\mathrm{S}_{\mathrm{irA}}$ & 1 \\
\hline$\lambda$ & 0.45 \\
\hline $\mathrm{P}_{0}$ & $10^{5} \mathrm{~Pa}$ \\
\hline $\begin{array}{l}\text { Relative permeability model } \\
\text { (Moridis et al., 2009a) }\end{array}$ & $\begin{array}{l}\mathrm{k}_{\mathrm{rA}}=\left(\mathrm{S}_{\mathrm{A}}^{*}\right)^{\mathrm{n}} \\
\mathrm{k}_{\mathrm{rG}}=\left(\mathrm{S}_{\mathrm{G}}^{*}\right)^{\mathrm{n}} \\
\mathrm{S}_{\mathrm{A}}^{*}=\left(\mathrm{S}_{\mathrm{A}}-\mathrm{S}_{\mathrm{irA}}\right) /\left(1-\mathrm{S}_{\mathrm{irA}}\right) \\
\mathrm{S}_{\mathrm{G}}^{*}=\left(\mathrm{S}_{\mathrm{G}}-\mathrm{S}_{\mathrm{irG}}\right) /\left(1-\mathrm{S}_{\mathrm{irA}}\right) \\
\text { OPM model }\end{array}$ \\
\hline n (Moridis et al., 2009a) & 5 \\
\hline $\mathrm{S}_{\mathrm{irG}}$ & 0.03 \\
\hline $\mathrm{S}_{\mathrm{irA}}$ & 0.30 \\
\hline
\end{tabular}

than $\mathrm{Q}_{\mathrm{R}}$ of gas release rate from hydrates, which implies that most gas produced at the well is not generated by hydrate dissociation but from the dissolved gas in the reservoir, and thereby that the productivity of gas from hydrate by depressurization is considerably small. Concretely speaking, $Q_{R}$ drops rapidly at the beginning of the production. This is attributed to a combination of (a) a decrease in the driving force of depressurization as the pressure differential between the well and the HBL is reduced rapidly and (b) the resulting lower T, which further slows dissociation. The drop of $Q_{p}$ is relatively small because of (a) gas accumulation in the deposit, as the released gas at the advancing dissociation fronts cannot yet be produced at the well because the hydraulic diffusion $\mathrm{k}_{\mathrm{g}}$ of the formation is too small, and (b) the pressure gradient $\nabla \mathrm{p}$ between the well and the reservoir in addition to the gas release rate $Q_{R}$. The average gas production rate $\bar{Q}_{\mathrm{P}}$ over 3.5 years is merely $211 \mathrm{~m}^{3} / \mathrm{d}$ but still much greater than the average gas release rate $\bar{Q}_{R}\left(11 \mathrm{~m}^{3} / \mathrm{d}\right)$ over the same period. The production rate in the reference case is much less than the absolute criterion for economical production (Moridis et al., 2009a).

Fig. 5 shows the cumulative volumes (a) $\mathrm{V}_{\mathrm{P}}$ of total produced $\mathrm{CH}_{4}$, and (c) $\mathrm{V}_{\mathrm{R}}$ of $\mathrm{CH}_{4}$ released from hydrates in the entire simulated domain and (d) $V_{G}$ of free $\mathrm{CH}_{4}$ remained in the reservoir. The amount of gas produced at the well $V_{P}$ is much bigger than that released from hydrate deposits. $V_{P}$ and $V_{R}$ keep increasing obviously but $V_{G}$ always keeps invariant as the production goes on. During the production duration of 3.5 years, a total of $\mathrm{V}_{\mathrm{P}}=2.7 \times 10^{5} \mathrm{ST} \mathrm{m}^{3}$ of $\mathrm{CH}_{4}$ is produced but practically only $1.4 \times 10^{4} \mathrm{ST} \mathrm{m}^{3}$ of $\mathrm{CH}_{4}$ is released from crystalline hydrate. At the end of this simulation period, the hydrate is far from exhausted, and $V_{R}=0.05 \quad V_{P}$ and $V_{D G}=V_{P}-V_{R}-V_{G}=2.5 \times$ $10^{5} \mathrm{ST} \mathrm{m}^{3}\left(\mathrm{~V}_{\mathrm{DG}}\right.$ is cumulative volume of $\mathrm{CH}_{4}$ produced from dissolved gas $)$, which means $92 \%\left(=V_{\mathrm{DG}} / \mathrm{V}_{\mathrm{PT}}\right)$ of produced gas is from dissolved gas in pore water.

Fig. 6 shows (a) $Q_{W}$ of the water production rate and (b) $R_{G W}$ of volumetric ratio of the cumulative gas $V_{P}$ to the cumulative water $\mathrm{V}_{\mathrm{W}}\left(=\mathrm{M}_{\mathrm{W}} / 1030\right)$ produced at the well. $\mathrm{Q}_{\mathrm{W}}$ increases slightly at the first-half production period and then sustains its stability approximately, the average water production rate is $5.4 \times 10^{4} \mathrm{~kg} / \mathrm{d}(=54 \mathrm{t})$ $\mathrm{d}=52 \mathrm{~m}^{3} / \mathrm{d}$ ). The high and stable water production rates are consistent with the stable gas production rate and the small gas release rate, and prove that most gas produced at the screened interval is evolved from water solution. Fig. 6 also shows the economical efficiency of gas production from the hydrate deposits. $\mathrm{R}_{\mathrm{GW}}\left(=\mathrm{V}_{\mathrm{PT}} / \mathrm{V}_{\mathrm{W}}\right)$ falls rapidly from a higher initial value to $\sim 4$ at the end of the production. This says that $4 \mathrm{ST} \mathrm{m}^{3}$ gas can be produced for producing $1 \mathrm{~m}^{3}$ water as byproduct in the hydrate production. This quantity provides an additional criterion for the determination of the production potential for a gas hydrate deposit. Fig. 6 implies that much money is wasted on water elevation and disposal if a production is invested.

\subsubsection{Spatial distributions of $S_{H}$}

Fig. 7 shows the evolution of the $S_{H}$ distribution over time in the deposit near the wellbore $(\mathrm{r}<30 \mathrm{~m})$. The dissociation pattern is unique due to the hydrate deposit type and special well configuration. These include (i) hydrate dissociation proceeding radially along the perforated well, (ii) the evolution of the upper and lower dissociation interfaces, and (iii) the evolution of the hydrate dissociation front.

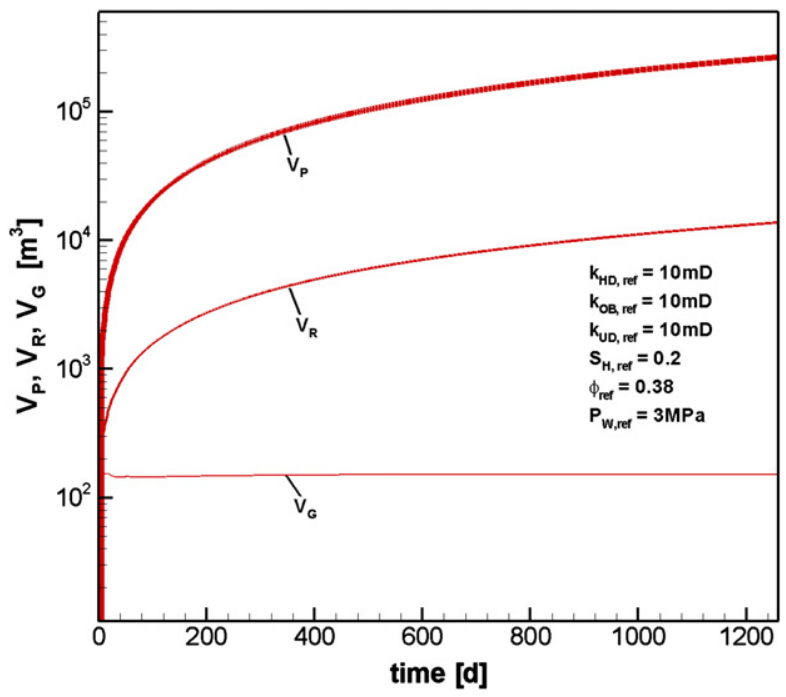

Fig. 5. Evolution of $V_{P}, V_{R}$ and $V_{G}$ during production from the vertical well.

Fig. 4. Evolution of $Q_{P}$ and $Q_{R}$ during production from the vertical well. 


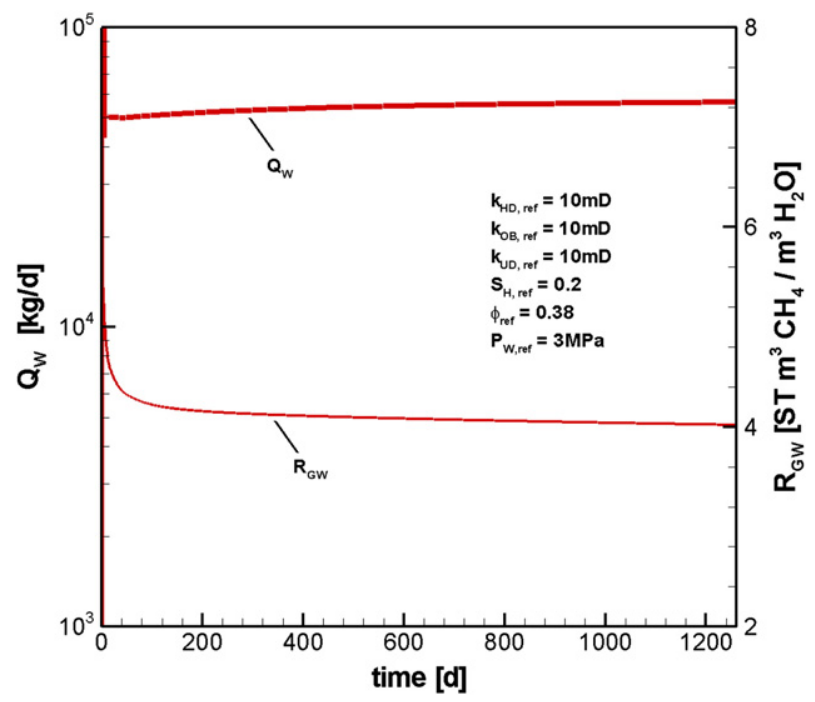

Fig. 6. Evolution of $\mathrm{Q}_{W}$ and $\mathrm{R}_{\mathrm{GW}}$ during production from the vertical well.

The hydrate dissociation proceeds along the perforated well initially and is more pronounced toward the top hydrate interface. The quicker dissociation at the top hydrate interface is due to the milder water pumping downward from the overlying water zone. The surface area of dissociation front enlarges radially and the hydrate seal restraining water from flooding into the perforated interval in the early time was broken through. But the gas production rate in Fig. 4 does not have an evident drop, which implies that the contribution of hydrate dissociation to gas production is small and thus the hydrate seal around the well appears useless. The dissociation radius is $\sim 4 \mathrm{~m}$ in the whole production duration.

\subsubsection{Spatial distributions of $S_{G}$}

The $\mathrm{S}_{\mathrm{G}}$ distributions in Fig. 8 indicate the contours of free gas between the production well and the hydrate dissociation front. Free gas is enveloped in the hydrate-free zone, but gas zone becomes smaller as the production proceeds. Its left end connects the production well and its right end reaches the dissociation front. The gas tail is shifting down and points to the most intense dissociation zone at the lower dissociation interface. The reasons for gas zone becoming smaller are the declining hydrate dissociation and the continuing gas recovery. The narrowing gas zone also implies a reduction in gas production rate and gas mobility. These are consistent with the process of hydrate dissociation in Fig. 7 and production performance in Figs. 3 and 5. The $S_{G}$ distributions in Fig. 8 also indicate there is no free gas loss that may be caused by the lack of an upper boundary in the hydrate system during the production.

\subsubsection{Spatial distributions of $T$ and $P$}

Temperature change happens in hydrate production because of the endothermic reaction. The T distribution in Fig. 9 indicates continuous cooling in the shallower zone and warming in the deeper zone as the dissociation and production proceed. The changes are slight in the contours but confirm expectations. The shallow cooling is because of endothermic process of hydrate dissociation and cool water influx from the overlying sediment, the deeper warming is caused by warm water influx from the underlying water zone (indicated in Fig. 11). Generally the temperature change in the contours is unapparent because of the ineffective hydrate dissociation and thermal diffusion in the sediment (Su et al., 2011).

The production of the laminar hydrate reservoir is operated with a constant pressure of $3 \mathrm{MPa}$ at the bottom-hole. The bottom-hole pressure is much lower than the equilibrium pressure for hydrate stability and intact sediment pressure. The low pressure at the production well can transmit in the sediment as fluids produce and hydrate dissociates, therefore the pressure change in the contours is related to hydrate dissociation rate and fluid production efficiency. Fig. 10 shows the pressure change in the production system by the depressurization. The color in the contours becoming weak as production proceeds indicates the pressure decreasing and the extension of the low-pressure zone in the sediment, but the slight change implies that the hydrate dissociation and the fluid production are inefficient.

\subsubsection{Spatial distributions of $X_{S}$}

The distribution of the salt concentration (expressed as the mass fraction of salt in the aqueous phase) in Fig. 11 shows the dilution effect of dissociation on salinity. Because salts cannot be included in the
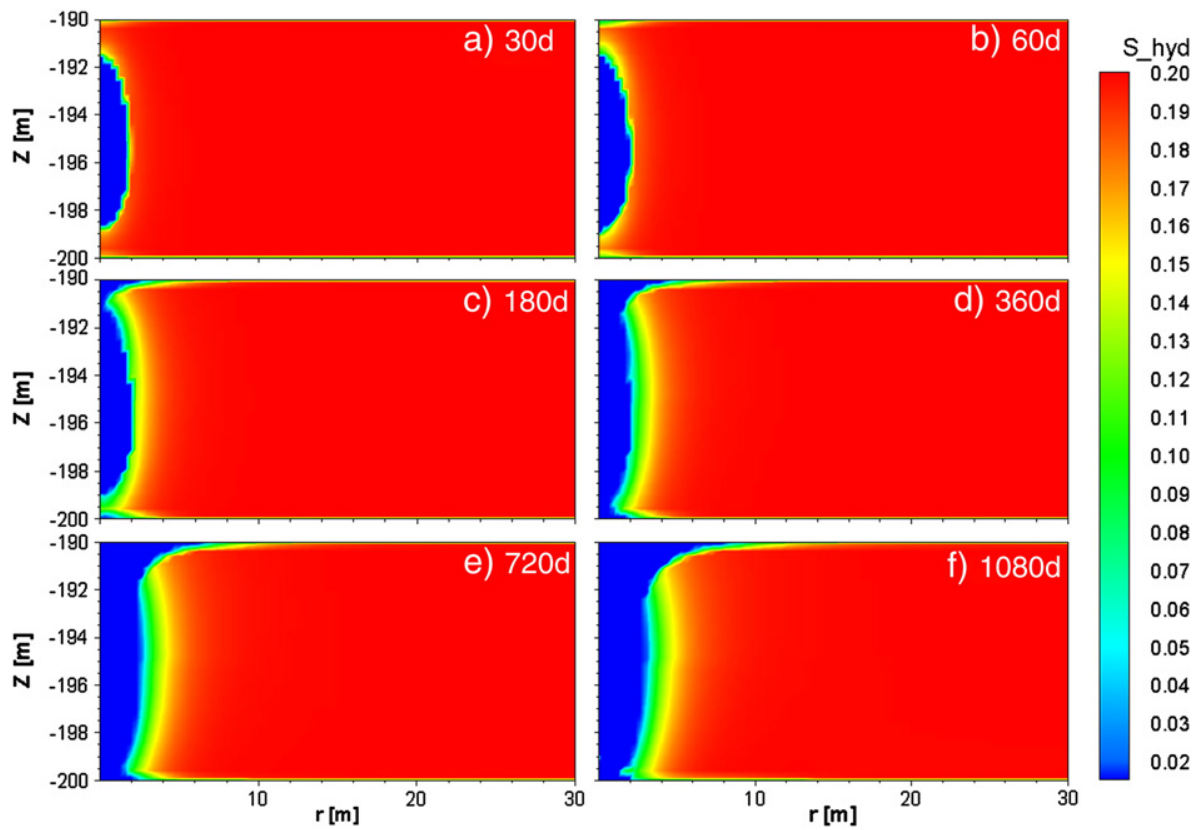

Fig. 7. Evolution of hydrate saturation $S_{H}$ during production from the vertical well. 

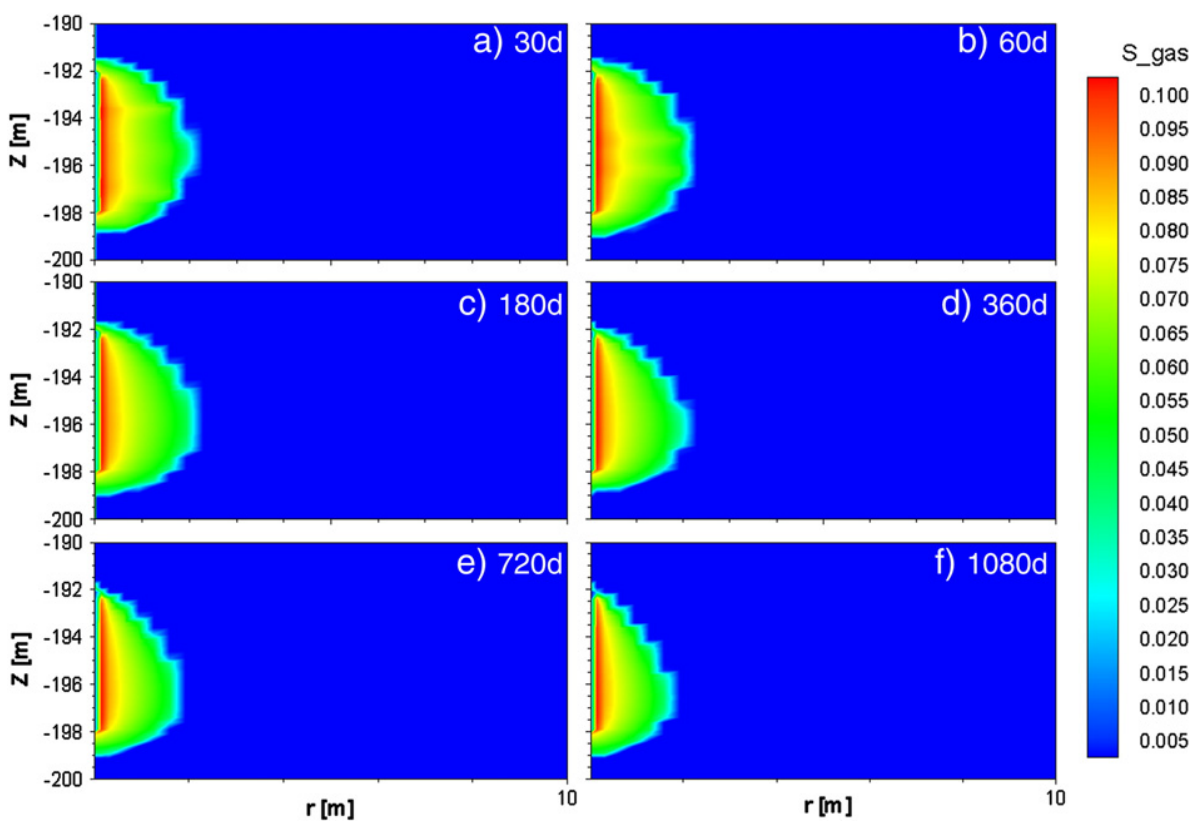

Fig. 8. Evolution of gas saturation $\mathrm{S}_{\mathrm{G}}$ during production from the single vertical well.

hydrate crystals, fresh water is released upon dissociation and reduces the water salinity. Thus, the locations of intense dissociation were identified as the loci of low salinity. The blue loci shown as $\mathrm{X}_{S}$ reduction at the dissociation front in the early stage of the production are because of intensive hydrate dissociation and dilution. The disappearance of the blue spots in the late period is attributed to the inefficient hydrate dissociation and the continuing removal (through production), dilution, and drainage of the native saline water. The
$\mathrm{X}_{\mathrm{S}}$ reduction shown as a long green zone in the lower HBL connecting the dissociation front is caused by a combination of water pumping and dilution. Fading of the green color in the late stages explicates the feeble hydrate dissociation and water pumping through the sediment. The red zones denoting high salinity in the HBL represent water invasion from the water zones and flooding pathways. The flooding sustains the production of water and dissolved gas, but restrains the hydrate dissociation.
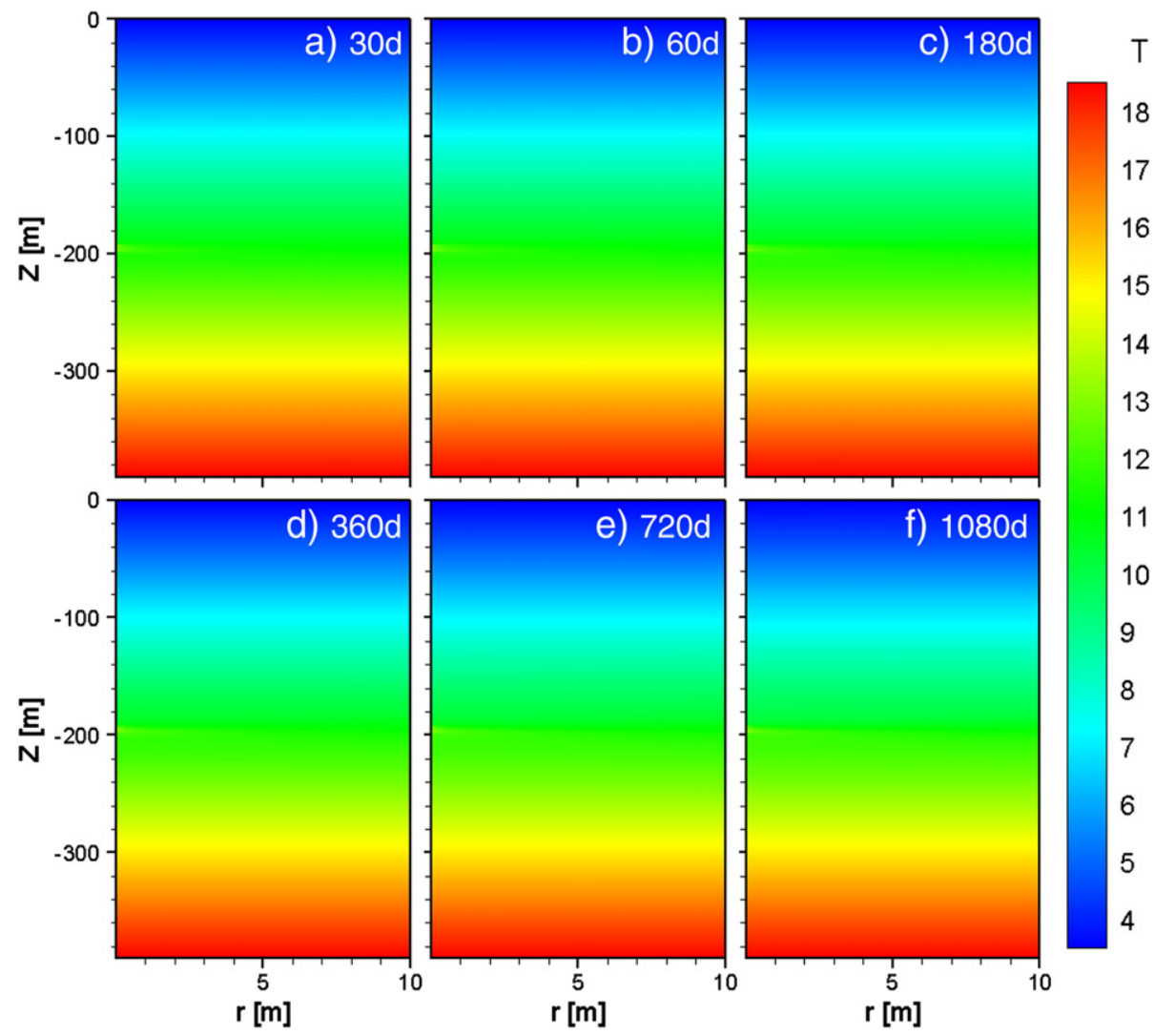

Fig. 9. Evolution of temperature T during production from the vertical well. 


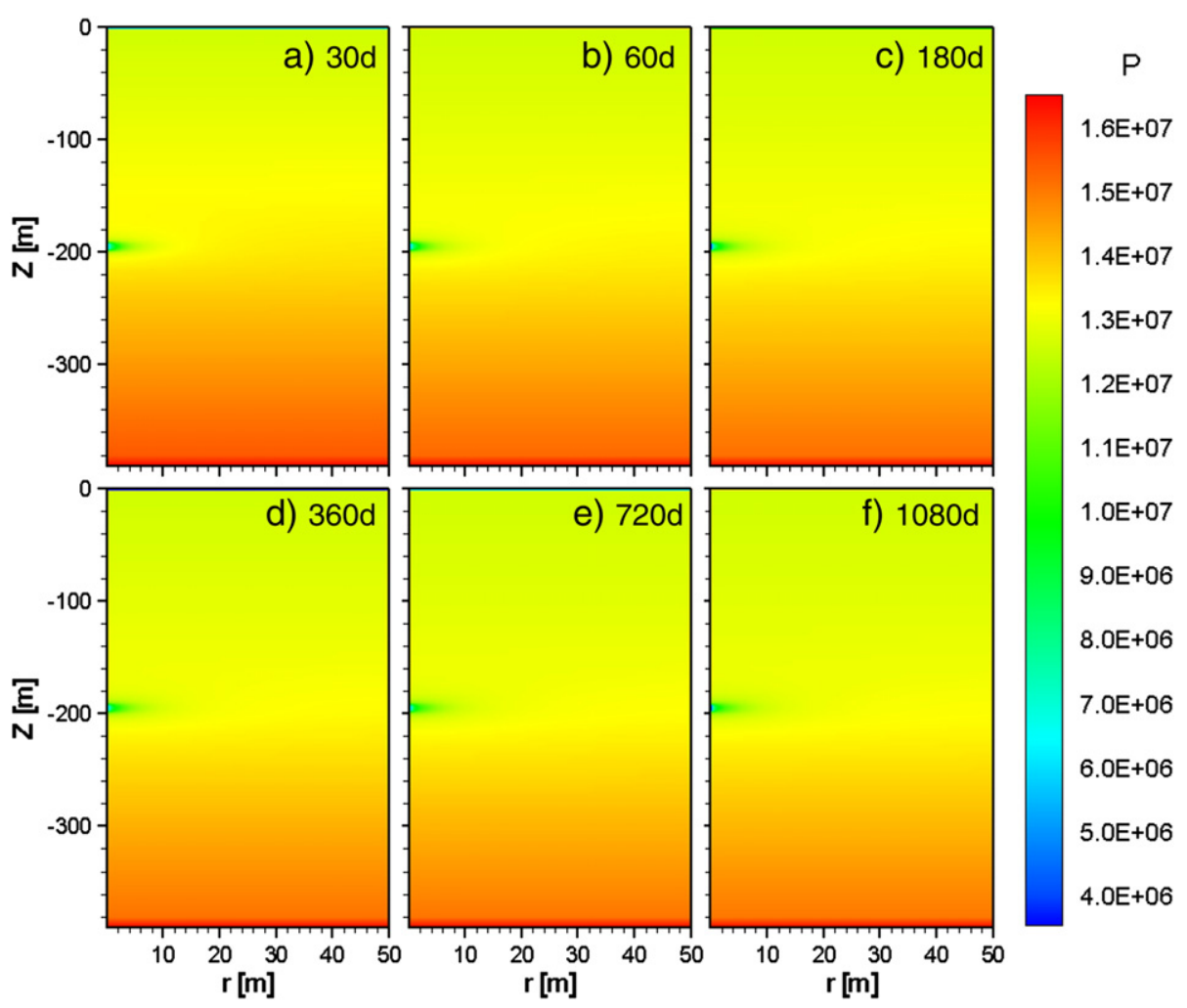

Fig. 10. Evolution of temperature P during production from the vertical well.

\subsection{Sensitivity analysis of gas production potential}

In these deposits, we investigated the sensitivity of gas production with the following conditions and parameters (Table 3):
(a) The bottom-hole pressure, $\mathrm{P}_{\mathrm{W}}$
(b) The initial hydrate saturation, $\mathrm{S}_{\mathrm{H}}$
(c) The intrinsic permeability, $\mathrm{k}$
(d) The impermeable overburden, $\mathrm{k}_{\mathrm{OB}}$

The reference case of researches in Figs. 12 through 23 is underlined in black line.

\subsubsection{Sensitivity to $P_{W}$}

In these simulations, gas is produced from the $\mathrm{SH} 3$ hydrate deposit by depressurization at a constant bottom-hole pressure $\mathrm{P}_{\mathrm{w}}$. In the reference case, we use the well pressure of $3 \mathrm{MPa}$ that is greater than the quadruple point. By increasing $\mathrm{P}_{\mathrm{W}}$ to $4 \mathrm{MPa}$ and $5 \mathrm{MPa}$, we observe deterioration in production performance, as evaluated using the
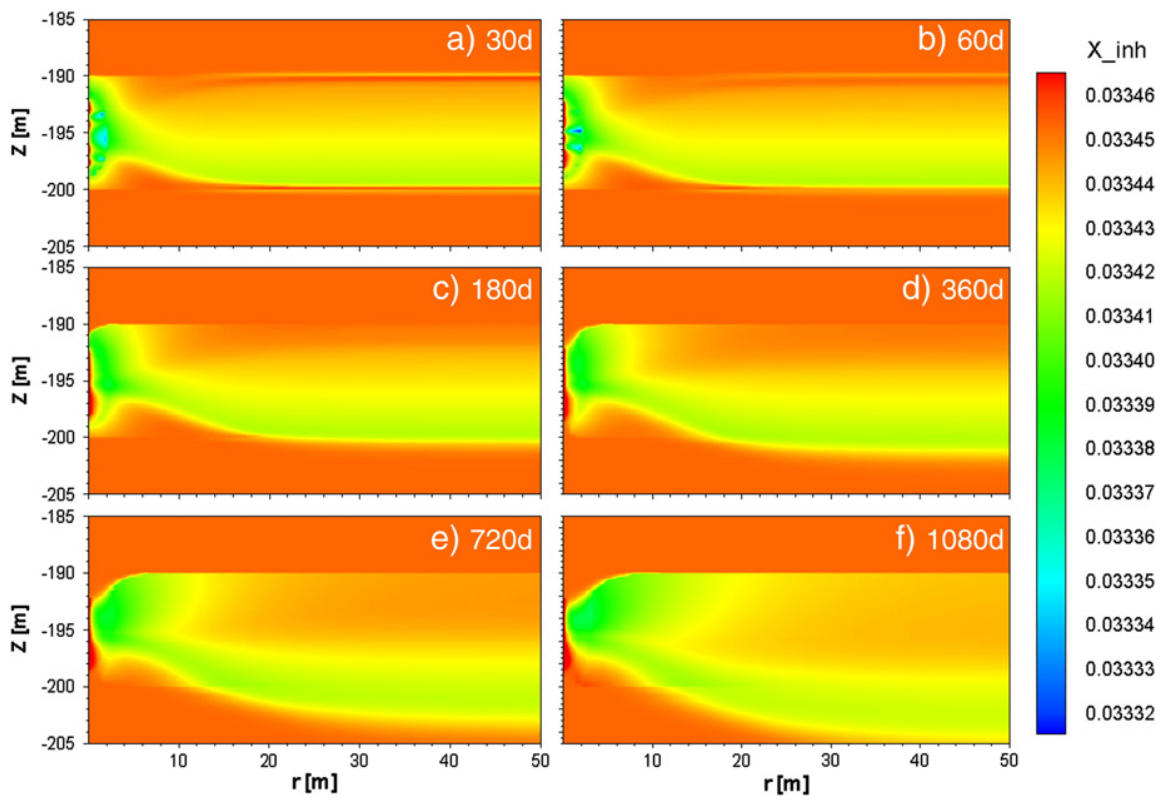

Fig. 11. Evolution of salt-inhibitor mass fraction $\mathrm{X}_{\mathrm{S}}$ in aqueous phase during production from the vertical well by depressurization. 
Table 3

Variables of the hydrate deposit used in the simulations.

\begin{tabular}{ll}
\hline Variables & Value \\
\hline Hydrate saturation $\mathrm{S}_{\mathrm{H}}$ in the $\mathrm{HBL}$ & $\mathrm{S}_{\mathrm{H}}=0.10$ \\
& $\mathrm{~S}_{\mathrm{H}}=0.20$ (reference value) \\
& $\mathrm{S}_{\mathrm{H}}=0.30$ \\
& $\mathrm{k}=10 \mathrm{mD}$ (reference value) \\
Intrinsic permeability of the $\mathrm{HBL}$ & $\mathrm{k}=50 \mathrm{mD}$ \\
& $\mathrm{k}=100 \mathrm{mD}$ \\
& $\mathrm{k}=10 \mathrm{mD}$ (reference value) \\
Intrinsic permeability of the $\mathrm{OB}$ & $\mathrm{k}=0.01 \mathrm{mD}$ (as a boundary) \\
& $\mathrm{Pw}=3 \mathrm{Ma}$ (reference value) \\
Bottom-hole pressure & $\mathrm{PW}=4 \mathrm{Ma}$ \\
& $\mathrm{PW}=5 \mathrm{Ma}$ \\
& $\mathrm{X}_{\mathrm{in}}=0.0334$ \\
Water salinity (mass fraction) & $\phi=0.38$ \\
Sediment porosity &
\end{tabular}

absolute criterion and the results in Figs. 12 and 13. The effect of increasing $\mathrm{P}_{\mathrm{W}}$ is negative on $\mathrm{Q}_{\mathrm{P}}$ of total gas production rate and $\mathrm{V}_{\mathrm{P}}$ of total volume gas produced, $Q_{R}$ of gas release rate from hydrate and $V_{R}$ of cumulative gas released from hydrate. $V_{p}$ decreases by $7.8 \%$ for $1 \mathrm{MPa}$ elevation of $\mathrm{P}_{\mathrm{W}}$ and the total fall is $1.9 \times 10^{4} \mathrm{~m}^{3}, \mathrm{~V}_{\mathrm{r}}$ decreases by $10.7 \%$ and the total fall is $0.13 \times 10^{4} \mathrm{~m}^{3}$, meanwhile $V_{g}$ of free gas remained in the reservoir has a more pronounced decrease for the pressure changes. A $\mathrm{P}_{\mathrm{W}}$ elevation results in a small decrease in $V_{r}$, but big falls in $V_{p}$ and $V_{g}$, which suggests that gas production is mainly derived from dissolved gas rather than hydrate dissociation.

Water production is reduced evidently when the bottom-hole pressure is elevated (see $\mathrm{Q}_{w}$ in Fig. 14), but this positive effect is negated by the gas production decrease. The falls in water production are consistent with the feature of the gas production, which explicates that the gas production is determined by water output and confirms the previous cognition. Performance against the relative criterion of $R_{G W}$ (see $R_{G W}$ in Fig. 14) generally does not show an evident improvement. Thus increasing $\mathrm{P}_{\mathrm{W}}$ has an adverse effect on hydrate dissociation and gas production potential, but does not have evident influence on $\mathrm{R}_{\mathrm{GW}}$ performance.

\subsubsection{Sensitivity to $S_{H}$}

The hydrate saturation ranges from 0.12 to 0.26 and the average value of 0.20 has been used as the reference value. So it is practical to investigate the sensitivity of $\mathrm{S}_{\mathrm{H}}$ to gas production performance. As shown in Fig. 15, gas production rate at the well $Q_{p}$ and the gas

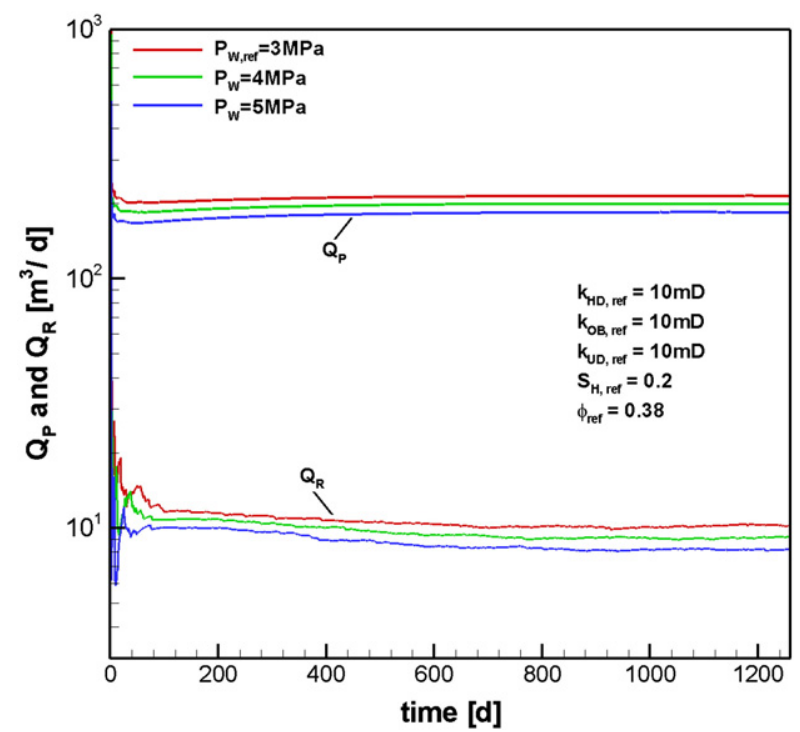

Fig. 12. Evolution of $Q_{P}$ and $Q_{R}$ during production and their sensitivity to the variations in bottom-hole pressure $\mathrm{P}_{\mathrm{w}}$.

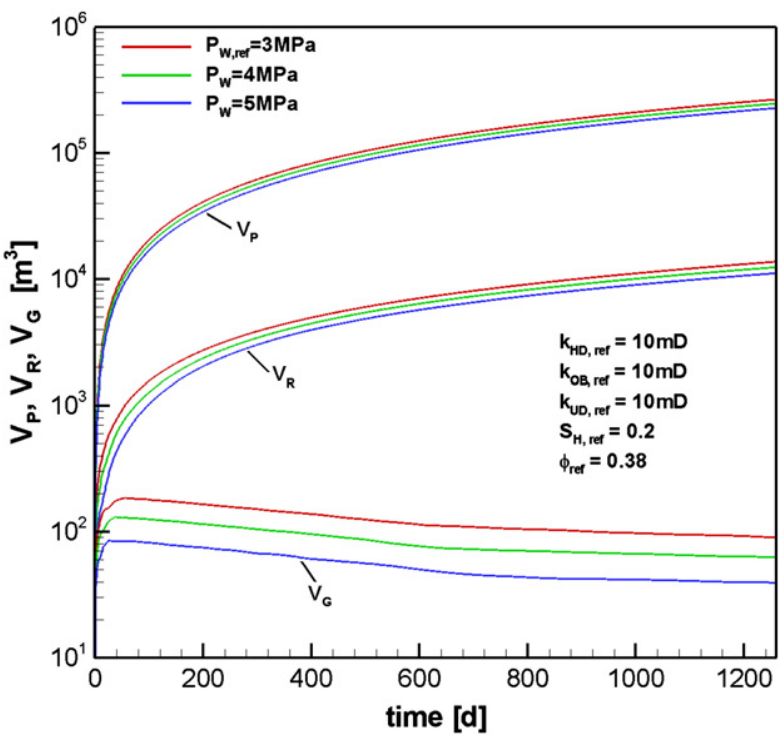

Fig. 13. Evolution of $V_{P}, V_{R}$, and $V_{G}$ during production and their sensitivity to the variations in bottom-hole pressure $\mathrm{P}_{\mathrm{W}}$.

release rate from hydrate $Q_{R}$ depend on the initial hydrate saturation $S_{H}$. A high $S_{H}$ leads to a small $Q_{P}$ and a big $Q_{R}$ at the early period of the production. But $Q_{P}$ is less sensitive to $S_{H}$ in the early period since free gas cannot be produced effectively from the sediment of low hydraulic diffusion and is more insensitive to $S_{H}$ in the late period of the production because of the pressure gradient decline and inefficient hydrate dissociation. $Q_{R}$ becomes inert for the higher $S_{H}$ at the late period because of the reduced pressure gradient and displeasing water flooding.

The behavior of SH3 hydrate production is also illustrated by the evolution of the cumulative volume of produced gas $V_{P}$, gas released from hydrate $V_{R}$, and free gas remaining in reservoir $V_{G}$ (Fig. 16). A higher gas production is corresponding to a smaller hydrate saturation, but the production differences are very slight in the production duration. $V_{R}$ and $V_{G}$ depend on $S_{H}$ though the sensitive effect becomes inconspicuous at the end of the productions. The abnormal relations imply that the gas released from hydrate cannot be produced efficiently, and that the higher water production at the smaller $\mathrm{S}_{\mathrm{H}}$ is attributed to the increased water output, and suggest that a higher $S_{H}$ could improve hydrate dissociation but reduce the hydraulic diffusion

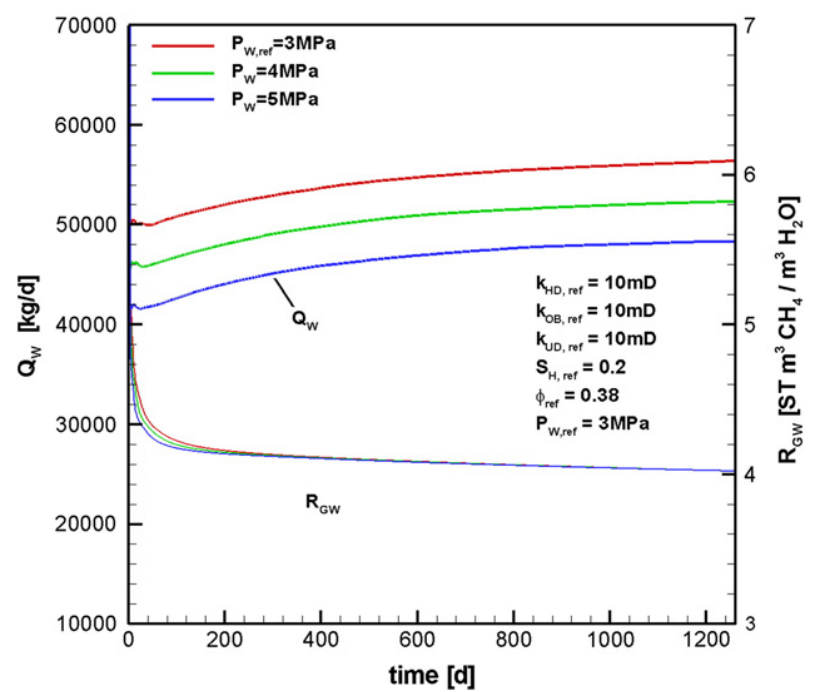

Fig. 14. Evolution of $\mathrm{Q}_{W}$ and $\mathrm{R}_{\mathrm{GW}}$ during production and their sensitivity to the variations in bottom-hole pressure $\mathrm{P}_{\mathrm{W}}$. 


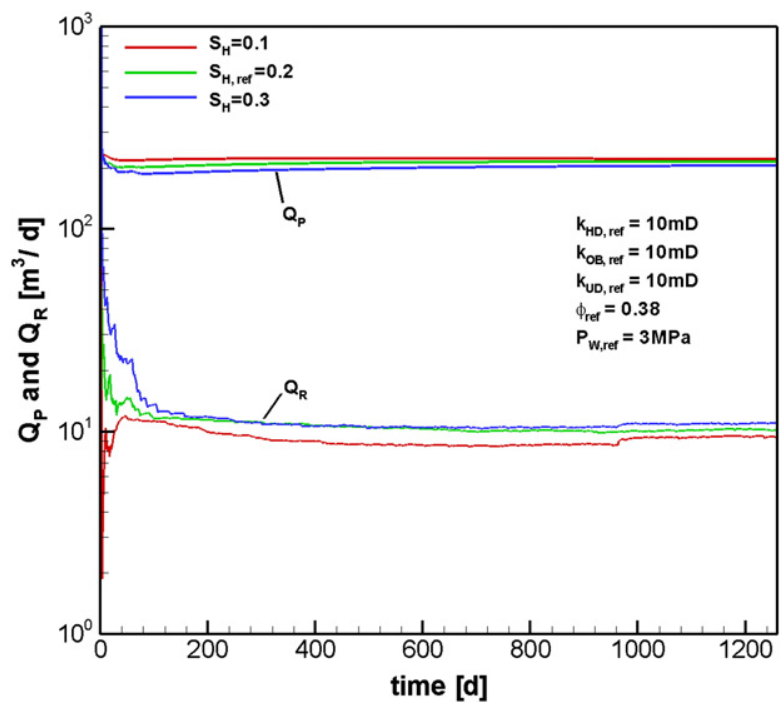

Fig. 15. Effect of hydrate saturation $S_{H}$ on $Q_{P}$ and $Q_{R}$.

of the sediment as well as the fluid production. The fact that $V_{P}$ exceeds $V_{R}$ in Fig. 16 shows that most of the gas production does not originate from the hydrate but from gas dissolved in the water. Because of the very small solubility of $\mathrm{CH} 4$ in water, this would mean a tremendous water production for a practical level of production, and indicates that this is not a very promising deposit or approach.

Fig. 17 shows effect of $S_{H}$ on water production rate $Q_{W}$ and gas efficiency relative to water production $R_{G W}$. A lower $S_{H}$ results in a higher $\mathrm{Q}_{\mathrm{W}}$ but a lower $\mathrm{R}_{\mathrm{GW}}$. The reason is obvious. More water can be produced from a deposit of a low $\mathrm{S}_{\mathrm{H}}$ by depressurization because of its high hydraulic diffusion. The produced dissolved gas is proportional to the water amount. But less gas from the hydrate deposit can be produced and thus a low $\mathrm{S}_{\mathrm{H}}$ leads to a reduced $\mathrm{R}_{\mathrm{GW}}$. The sensitivity becomes weak gradually as the production proceeds, which is attributed to the continuing decline in $\mathrm{Q}_{\mathrm{R}}$ and $\nabla \mathrm{p}$.

It is obvious that the initial hydrate saturation does not have strong effects on the gas production potential of the SH3 hydrate deposit in terms of both the absolute and the relative criteria. Hydrate dissociation rate and gas production rate are associated with the effective transmission of depressurization, which depends on the effective porosity and permeability of sediment. A higher $\mathrm{S}_{\mathrm{H}}$ means a

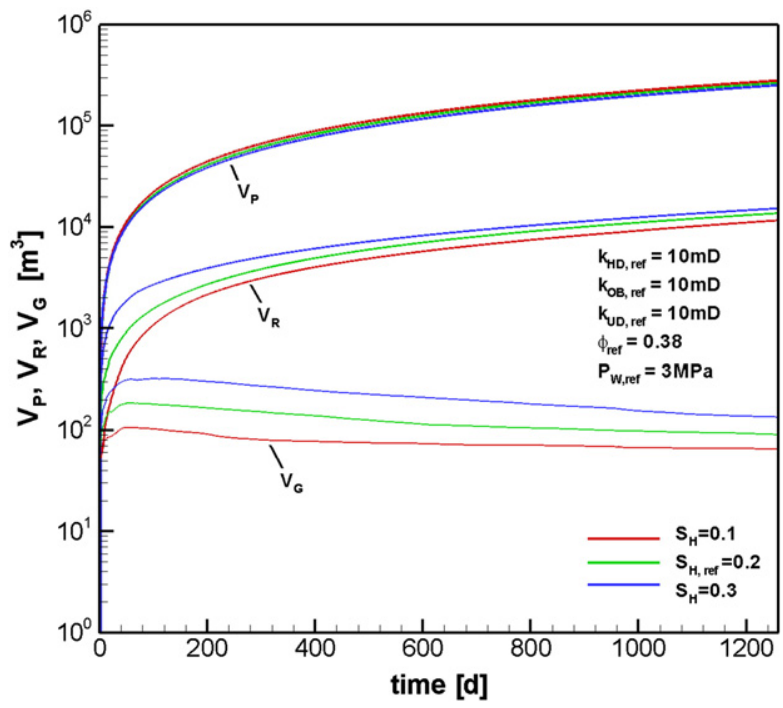

Fig. 16. Effect of hydrate saturation $S_{H}$ on $V_{P} V_{R}$, and $V_{G}$.

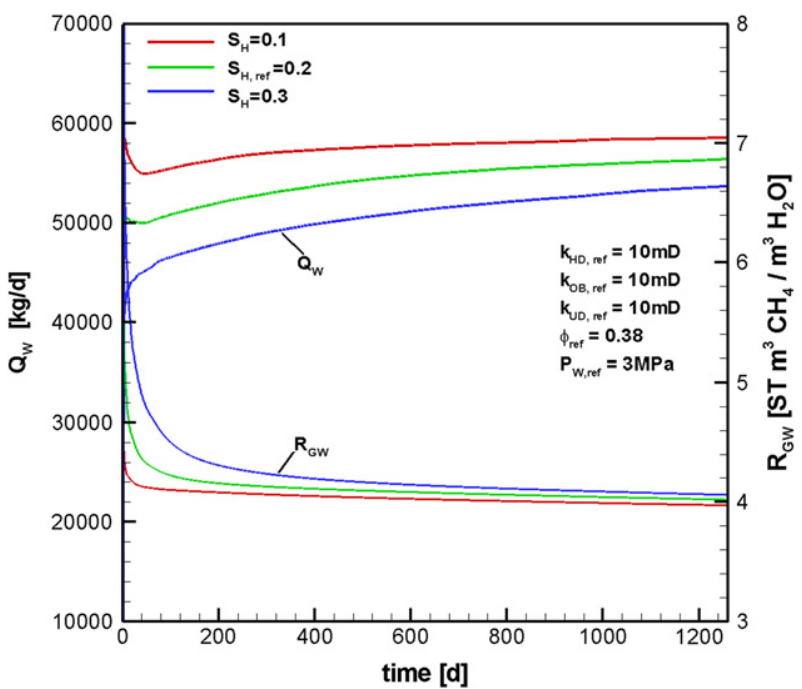

Fig. 17. Effect of hydrate saturation $S_{H}$ on $Q_{W}$ and $R_{G W}$.

reduced transmission of depressurization and thus results in a small elevation of gas production.

\subsubsection{Sensitivity to $k$}

Deposit permeability determines the effect of depressurization transmitting in reservoirs and fluid productivity. The permeability of SH3 hydrate-containing sediment used in the reference case is relatively small and may undermine the gas production potential. By elevating $\mathrm{k}$ to $50 \mathrm{mD}\left(=5.0 \times 10^{-14} \mathrm{~m}^{2}, 5\right.$ times of the reference value $)$ and $100 \mathrm{mD}\left(=1.0 \times 10^{-13} \mathrm{~m}^{2}, 100\right.$ times of the reference value), we observe enhancement in performance, as evaluated using the absolute criterion shown in Figs. 18 and 19. The effect of $k$ on $Q_{P}, V_{P}, V_{R}$, $\mathrm{Q}_{R}$, and $\mathrm{V}_{\mathrm{G}}$ is huge, but the increment of gas production at the well is much higher than that of gas released from hydrate. More released gas can be produced in case of high permeability, while water production can also be elevated (see $Q_{w}$ in Fig. 20) because of the ameliorative hydraulic diffusion. Performance against the relative criterion of $R_{G W}$ (see $R_{G W}$ in Fig. 20) is lower than that in the reference case. This shows that the increase rate of water output is higher than that of gas production. So the positive effect of the sediment permeability on producing gas is negated by the high water proportion in the

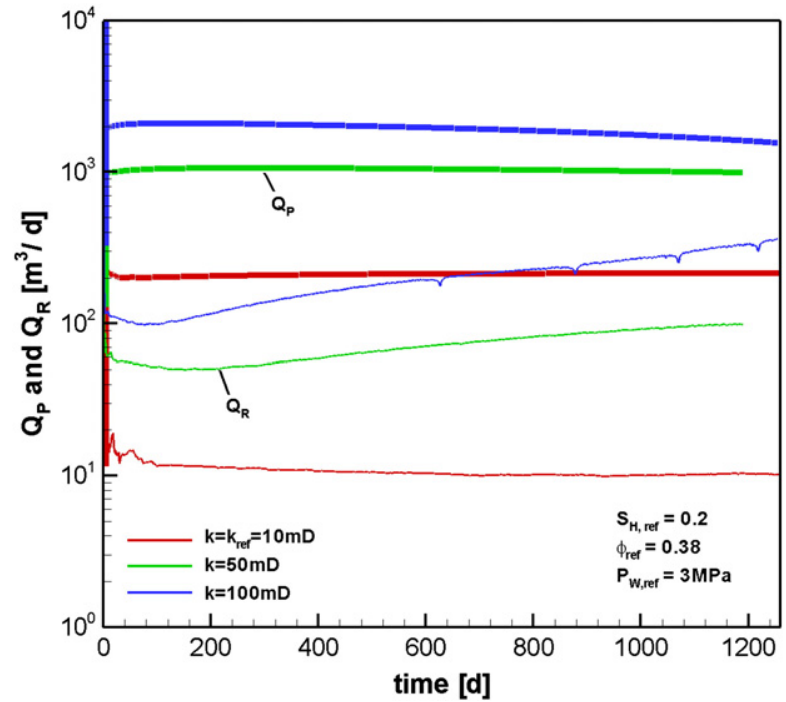

Fig. 18. Evolution of $Q_{P}$ and $Q_{R}$ during production and their sensitivity to variations in the intrinsic permeability $\mathrm{k}$ 


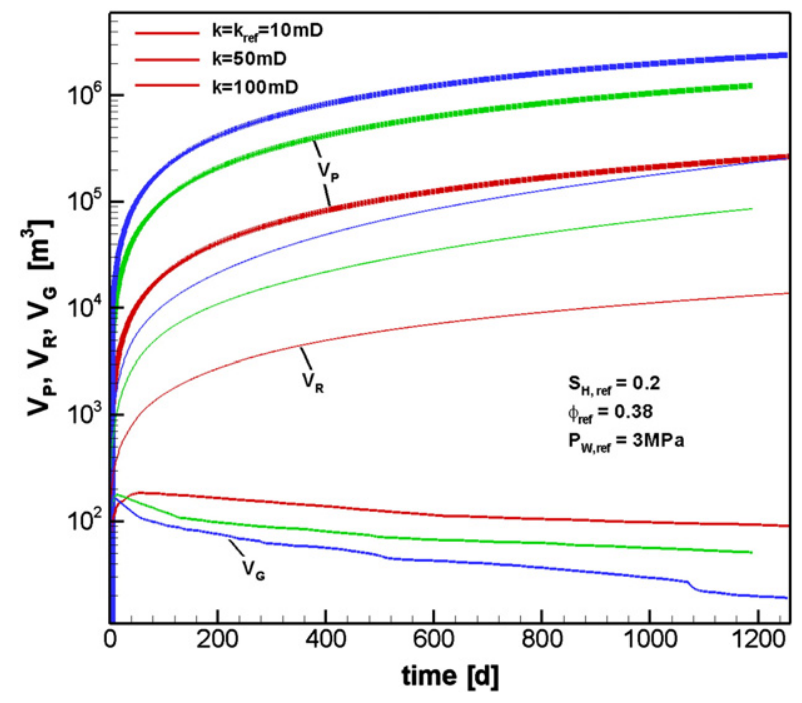

Fig. 19. Evolution of $V_{P}, V_{R}$, and $V_{G}$ during production and their sensitivity to variations in the intrinsic permeability $\mathrm{k}$.

produced fluids. The obvious conclusion is that an increasing $\mathrm{k}$ has a pronounced effect on the gas production potential but has to pay for high water production.

\subsubsection{Sensitivity to impermeable boundary}

The overburden of HBL in the simulated domain may act as a boundary that prevents free gas from escaping upward if its permeability $\left(\mathrm{k}_{\mathrm{OB}}\right)$ is lower than that of the HBL $(\mathrm{k})$. But the underburden of HBL may not act as an impermeable barrier because formation of a hydrate deposit necessitates a permeable underburden allowing fluid passing flow. So an ideal hydrate deposit for quick gas production is that of having an impermeable upper boundary. By reducing $\mathrm{k}_{\mathrm{OB}}$ from the reference value of $10 \mathrm{mD}$ to $0.01 \mathrm{mD}$, but $\mathrm{k}$ of HBL permeability and $\mathrm{k}_{\mathrm{UB}}$ of underburden permeability are kept invariant, the gas well performance is observed and shown in Figs. 21 through 23. The effect of $\mathrm{k}_{\mathrm{OB}}$ on gas release is less than that on gas production. The figures suggest that the impermeable boundary can elevate the gas

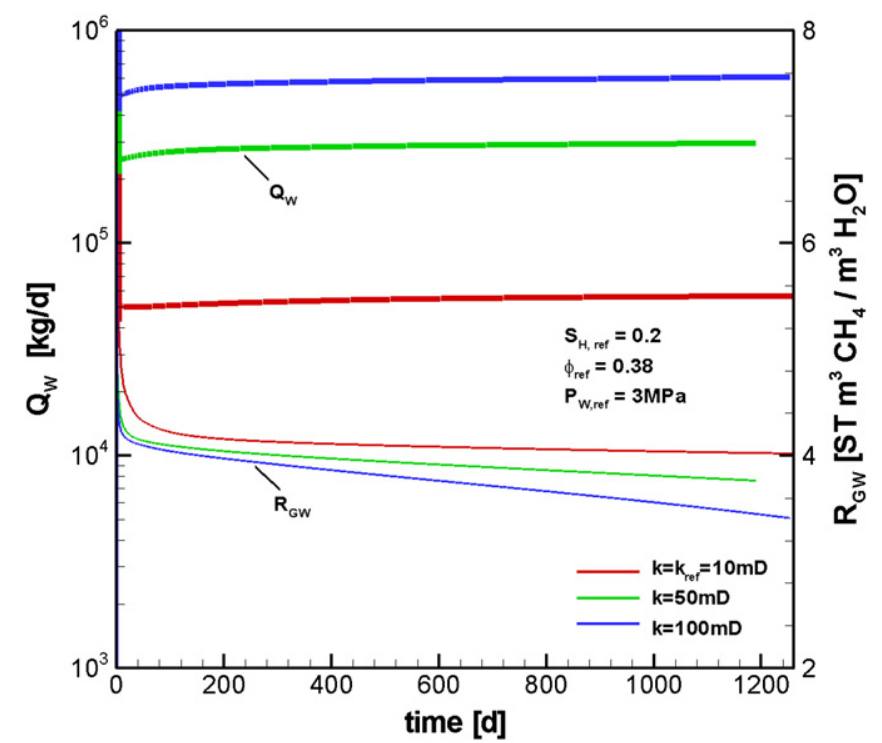

Fig. 20. Evolution of $\mathrm{Q}_{\mathrm{W}}$ and $\mathrm{R}_{\mathrm{GW}}$ during production and their sensitivity to variations in the intrinsic permeability $\mathrm{k}$.

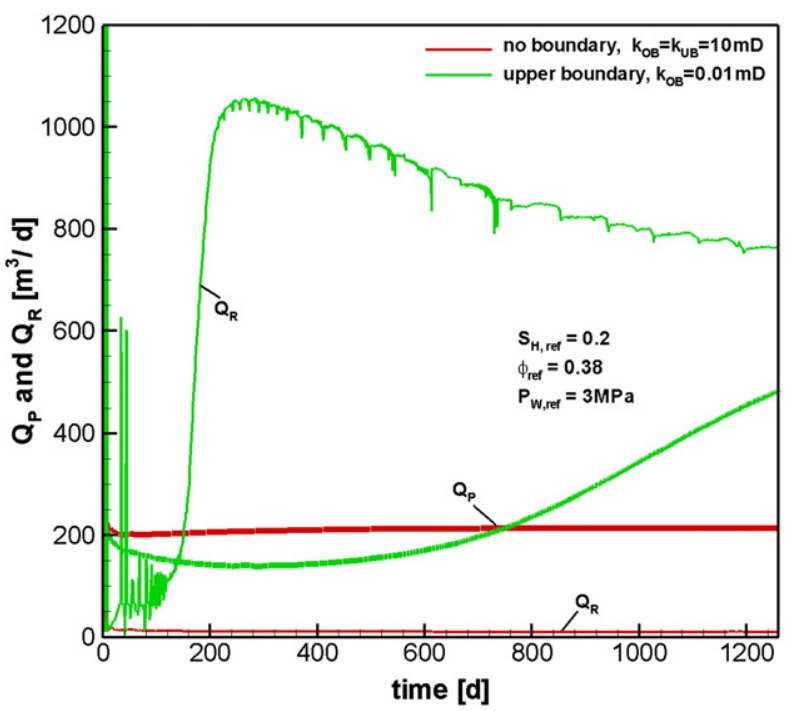

Fig. 21. Effect of overburden and underburden permeabilities $k_{O B}$ and $k_{U B}$ on $Q_{P}$ and $Q_{R}$.

release rate from the hydrate deposit and improve gas production performance.

Figs. 21 and 22 show that an upper boundary has a slightly negative contribution in gas production and gas release from the hydrate deposit. The reduction in gas release rate explicates that the impermeable overburden bates the transmission of depressurization in the deposit. The decreasing water production depresses the hydrate dissociation in a short period. An abrupt jump in gas release rate at production time of $200 \mathrm{~d}$ is due to a sufficient pressure transmission and a reduced pressure in the HBL. The slow increase in gas production at the late period is mainly attributed to the high gas release rate and efficient gas removal from the reservoir. In the new simulation the gas release rate is much higher than the gas production rate generally and thus leads to a result that the cumulative volume of gas that remained in the reservoir is higher than the total volume of gas produced. Gas volume increase in sediments improves the relative permeability of gas in the medium and thus enhances gas productivity and depresses the water output. Fig. 23 shows that $\mathrm{Q}_{w}$ in the upperboundary case is reduced substantially, and $\mathrm{R}_{\mathrm{GW}}$ is much higher than

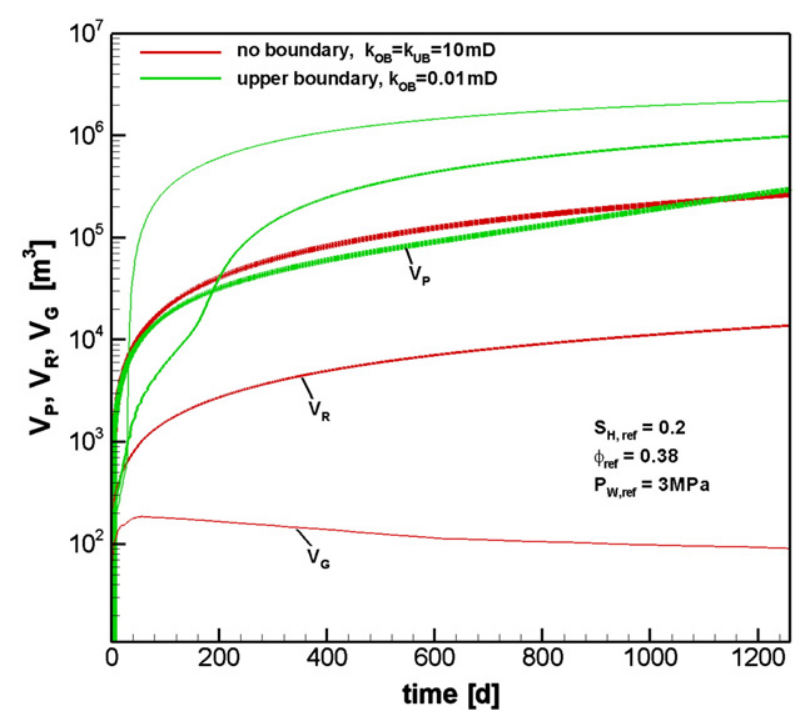

Fig. 22. Effect of overburden and underburden permeabilities $k_{\mathrm{OB}}$ and $\mathrm{k}_{\mathrm{UB}}$ on $\mathrm{V}_{\mathrm{P}}, \mathrm{V}_{\mathrm{R}}$ and $\mathrm{V}_{\mathrm{G}}$ 


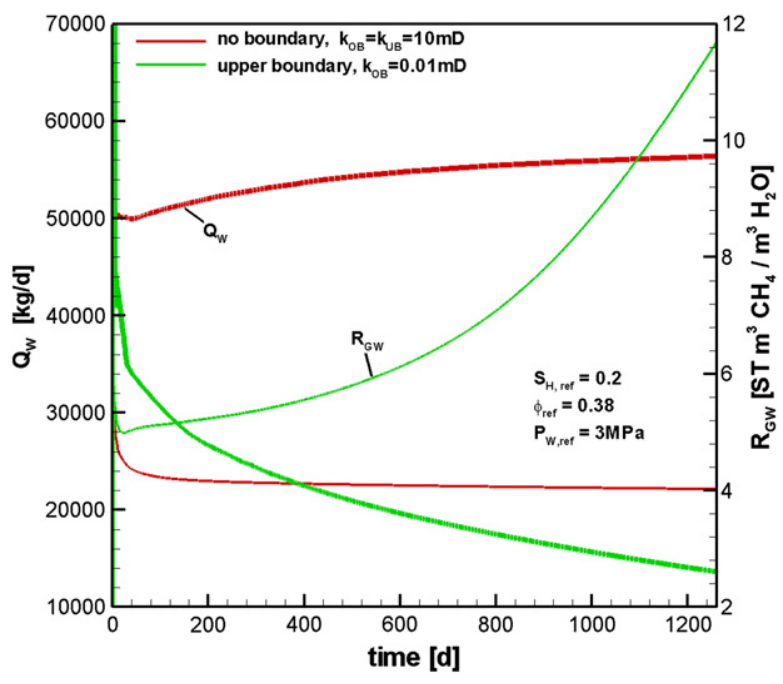

Fig. 23. Effect of overburden permeability $\mathrm{k}_{\mathrm{OB}}$ and underburden permeability $\mathrm{k}_{\mathrm{UB}}$ on $\mathrm{Q}_{\mathrm{W}}$ and $\mathrm{R}_{\mathrm{GW}}$.

that in the reference case especially at the end of the production duration. It is obvious to conclude that an impermeable boundary can effectively improve the gas production and depress the water production.

\section{Conclusion}

We investigated gas production potential of the laminar hydrate deposits at the drilling site of SH3 in Shenhu area on northern continental slope of SCS. A vertical well was designed to produce gas from the perforated interval at middle section of the well in the HBL by depressurization. In the reference case the average gas production rate

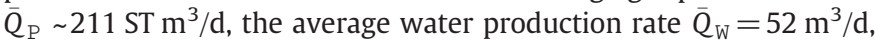
and the average ratio of gas to water production $\bar{R}_{\mathrm{GW}}=4\left(\mathrm{ST} \mathrm{m}^{3}\right.$ $\mathrm{CH}_{4} / \mathrm{m}^{3} \mathrm{H}_{2} \mathrm{O}$ ). Both the absolute criterion and the relative criterion suggested that gas production from the laminar hydrate deposits through a vertical well were not promising and of industrial potential. A desirable production from the laminar hydrate deposit needs novel production schemes and advanced well designs. Sensitivity analysis indicated that a high reservoir permeability and an impermeable boundary could substantially improve hydrate dissociation and gas production. These should be the principal targets in future hydrate survey.

\begin{tabular}{|c|c|}
\hline \multicolumn{2}{|c|}{ Nomenclature } \\
\hline$\Delta \mathrm{r}$ & Radial increment (m) \\
\hline$\Delta \mathrm{z}$ & Vertical discretization, i.e., in the z-direction (m) \\
\hline $\mathrm{C}$ & specific heat $(\mathrm{J} / \mathrm{kg} / \mathrm{K})$ \\
\hline $\mathrm{k}$ & intrinsic permeability $\left(\mathrm{m}^{2}\right)$ \\
\hline $\mathrm{k}_{\Theta}$ & thermal conductivity $(\mathrm{W} / \mathrm{m} / \mathrm{K})$ \\
\hline$k_{\Theta R D}$ & thermal conductivity of dry porous medium $(\mathrm{W} / \mathrm{m} / \mathrm{K})$ \\
\hline$k_{\Theta R W}$ & $\begin{array}{l}\text { thermal conductivity of fully saturated porous medium } \\
(\mathrm{W} / \mathrm{m} / \mathrm{K})\end{array}$ \\
\hline $\mathrm{M}_{\mathrm{W}}$ & cumulative mass of water produced at the well $(\mathrm{kg})$ \\
\hline $\mathrm{P}$ & pressure $(\mathrm{Pa})$ \\
\hline$Q_{P}$ & volumetric rate of $\mathrm{CH}_{4}$ production at the well $\left(\mathrm{ST} \mathrm{m}^{3} / \mathrm{s}\right)$ \\
\hline $\mathrm{Q}_{\mathrm{R}}$ & $\begin{array}{l}\text { volumetric rate of } \mathrm{CH}_{4} \text { release from hydrate dissociation } \\
(\mathrm{ST} \mathrm{m} / \mathrm{s})\end{array}$ \\
\hline $\mathrm{Q}_{\mathrm{W}}$ & mass rate of water produced at the well $(\mathrm{kg} / \mathrm{s})$ \\
\hline $\mathrm{r}, \mathrm{z}$ & coordinates $(\mathrm{m})$ \\
\hline$r_{w}$ & radius of the well assembly $(\mathrm{m})$ \\
\hline$r_{\max }$ & maximum radius of the simulation domain $(\mathrm{m})$ \\
\hline $\mathrm{R}_{\mathrm{GW}}$ & cumulative gas-to-water ratio ( $\mathrm{ST} \mathrm{m} \mathrm{CH}_{4} / \mathrm{m}^{3}$ water) \\
\hline$S$ & phase saturation \\
\hline
\end{tabular}

$\begin{array}{ll}\mathrm{t} & \text { time (days) } \\ \mathrm{T} & \text { temperature }\left(\mathrm{K} \mathrm{or}^{\circ} \mathrm{C}\right) \\ \mathrm{V}_{\mathrm{P}} & \text { Total volume of } \mathrm{CH}_{4} \text { produced at the well }\left(\mathrm{ST} \mathrm{m}^{3}\right) \\ \mathrm{V}_{\mathrm{R}} & \text { cumulative volume of } \mathrm{CH}_{4} \text { released from hydrate }\left(\mathrm{ST} \mathrm{m}{ }^{3}\right) \\ \mathrm{V}_{\mathrm{G}} & \begin{array}{l}\text { cumulative volume of } \mathrm{CH}_{4} \text { remaining in the reservoir } \\ \left.(\mathrm{ST} \mathrm{m})^{3}\right)\end{array} \\ \mathrm{X} & \text { mass fraction }(\mathrm{kg} / \mathrm{kg})\end{array}$

Greek symbols

$\lambda \quad$ van Genuchten exponent

$\varphi \quad$ porosity

$\begin{array}{ll}\text { Subscripts and superscripts } \\ \text { A } & \text { aqueous phase } \\ \text { cap } & \text { capillary } \\ \text { G } & \text { gas phase } \\ \text { H } & \text { solid hydrate phase } \\ \text { irG } & \text { irreducible gas } \\ \text { irA } & \text { irreducible aqueous phase } \\ \text { n } & \text { permeability reduction exponent } \\ \text { OB } & \text { overburden } \\ \text { UB } & \text { underburden }\end{array}$

\section{Acknowledgment}

This work was supported by the National Natural Science Foundation of China (No. 41076037), the National Basic Research Program of China (973 Program) (No. 2009CB219508), the China Geological Survey and the Lawrence Berkeley National Laboratory under the U.S. Department of Energy. We also thank the anonymous reviewers for their comments and suggestions to improve the quality of work.

\section{References}

Cathles, L.M., 2007. Changes in sub-water table fluid flow at the end of the Proterozoic and its implications for gas pulsars and MVT lead-zinc deposits. Geofluids 7 , 209-226.

Clarke, M.A., Bishnoi, P.R., 2000. Determination of the intrinsic rate of methane gas hydrate decomposition. Chem. Eng. Sci. 55, 4869.

Kim, H.C., Bishnoi, P.R., Heidemann, R.A., Rizvi, S.S.H., 1987. Kinetics of methane hydrate decomposition. Chem. Eng. Sci. 42 (7), 1645.

Li, G., Moridis, G.J., Zhang, K., Li, X., 2010. Evaluation of gas production potential from marine gas hydrate deposits in Shenhu Area of South China Sea. Energy Fuel 24, 6018-6033.

Makogon, Y.F., 1987. Gas hydrates: frozen energy. Recherche 18 (192), 1192.

Makogon, Y.F., 1997. Hydrates of Hydrocarbons. Penn Well Publishing Co., Tulsa, OK.

Moridis, G.J., Kowalsky, M., 2006. Gas production from unconfined Class 2 hydrate accumulations in the oceanic subsurface. Chapter 7 In: Max, M., Johnson, A.H., Dillon, W.P., Collett, T. (Eds.), Economic Geology of Natural Gas Hydrates. Kluwer Academic/Plenum Publishers, pp. 249-266.

Moridis, G.J., Reagan, M.T., 2007a. Strategies for gas production from oceanic Class 3 hydrate accumulations. OTC 18865, 2007 Offshore Technology Conference, Houston, Texas, U.S.A., 30 April-3 May 2007.

Moridis, G.J., Reagan, M.T., 2007b. Gas production from oceanic Class 2 hydrate accumulations. OTC 18866, 2007 Offshore Technology Conference, Houston, Texas, U.S.A., 30 April-3 May 2007.

Moridis, G.J., Sloan, E.D., 2007. Gas production potential of disperse low-saturation hydrate accumulations in oceanic sediments. J. Energy Convers. Manage. 48 (6), 1834-1849.

Moridis, G.J., Collett, T., Dallimore, S., Satoh, T., Hancock, S., Weatherhill, B., 2004. Numerical studies of gas production from several methane hydrate zones at the Mallik Site, Mackenzie Delta, Canada. J. Pet. Sci. Eng. 43, 219-239.

Moridis, G.J., Kowalsky, M., Pruess, K., 2007. Depressurization-Induced gas production from Class 1 hydrate deposits. SPE J. Reserv. Eval. Eng. 10 (5), 458-481.

Moridis, G.J., Reagan, M.T., Kim, S.-J., Seol, Y., Zhang, K., 2009a. Evaluation of the gas production potential of marine hydrate deposits in the Ulleung Basin of the Korean East Sea. SPE J. 14 (4), 759-781 SPE-110859-PA.

Moridis, G.J., Collett, T.S., Boswell, R., Kurihara, M., Reagan, M.T., Koh, C., Sloan, E.D., 2009b. Toward production from gas hydrates: current status, assessment of resources, and simulation-based evaluation of technology and potential. SPE Reserv. Eval. Eng. 12 (5), 745-771. 
Moridis, G.J., Collett, T.S., Pooladi-Darvish, M., Hancock, S., Santamarina, C., Boswell, R., Kneafsey, T., Rutqvist, J., Kowalsky, M., Reagan, M.T., Sloan, E.D., Sum, A.K., Koh, C., 2011. Challenges, uncertainties and issues facing gas production from gas hydrate deposits. SPE Reserv. Eval. Eng. 14 (1), 76-112.

Sloan, E.D., 1998. Clathrate Hydrates of Natural Gases. Marcel Decker, Inc., New York, NY.

Su, Z., Moridis, G.J., Zhang, K., Yang, R., Wu, N., 2010. Numerical investigation of gas production strategy for the hydrate deposits in the Shenhu area. OTC 20551, 2010 Offshore Technology Conference, Houston, Texas, U.S.A., 3-6 May 2010.

$\mathrm{Su}, \mathrm{Z}$., Cao, Y., Wu, N., He, Y., 2011. Numerical analysis on gas production efficiency from hydrate deposits by thermal stimulation: application to Shenhu Area, South China Sea. Energies 4, 294-313. van Genuchten, M.Th., 1980. A closed-form equation for predicting the hydraulic conductivity of unsaturated soils. Soil Sci. Soc. Am. J. 44, 892-898.

Wu, N., Yang, S., Zhang, H., Liang, J., Wang, H., Su, X., Fu, S., 2008. Preliminary discussion on gas hydrate reservoir system of Shenhu Area, North Slope of South China Sea. Proceedings of the 6th international conference on gas hydrates (ICGH 2008), 5700, Vancouver, British Columbia, Canada, 6-10 July 2008.

Wu, N., Yang, S., Zhang, H., Liang, J., Wang, H., Lu, J., 2010. Gas hydrate system of Shenhu Area, Northern South China Sea: Wire-line logging, geochemical results and preliminary resources estimates. OTC 20485, 2010 Offshore Technology Conference, Houston, Texas, U.S.A., 3-6 May 2010. 